\title{
Quebrando os tabús: corpo e subversión en tres poetas galegas $^{1}$
}

\author{
Breaking Taboos: Body and Subversion in three Female \\ Galician Poets
}

\author{
María Teresa Bermúdez Montes \\ Universidade de Vigo \\ bermudezteresa@uvigo.es \\ Recibido: febrero 2020. Aceptado: marzo 2020
}

Nothing meaningful exists outside of discourse. (Stuart Hall, Representation and the Media, 1997)

\begin{abstract}
Resumo: Partindo da reflexión sobre as regras do patriarcado e os límites materiais e discursivos que aquelas impoñen, observaremos como o estigma social da menstruación é cuestionado e subvertido, para crear espazos de liberdade e transgresión nos textos literarios. Ocuparémonos de analizar os mecanismos tradicionais do tabú —como silenciamiento e invisibilización-e a súa conexión co impuro e abxecto para, a seguir, poñer o foco na ruptura propositada coas limitacións. Exploraremos a representación da menstruación nas últimas décadas como manifestación dun corpo asumido e reivindicado, froito dun espírito crítico e dunha vontade de empoderamento con base no pensamento feminista. Para isto centrarémonos en textos poéticos de tres autoras galegas contemporáneas: Lupe Gómez, Yolanda Castaño e Estíbaliz Espinosa.
\end{abstract}

Palabras chave: Poesía galega, corpo feminino, menstruación, tabú, transgresión

Abstract: The aim of this paper is to develop a reflection on the rules of patriarchy and the material and discursive limits that they impose. The traditional mechanisms of taboo - such as silencing and invisibility - and its connection with the impure and abject will also be analyzed,by putting the focus on the concious break from the constraints imposed. The representation of

1 Esta pesquisa foi financiada polo proxecto «Cuerpos en tránsito 2: Diferencia e Indiferencia /Bodies in Transit 2: Difference and Indifference». Ref.: FFI2017-84555-C2-2-P, MINECO-FEDER (España). 
menstruation in recent decades will be explored as a manifestation of an assumed and claimed body, the result of a critical spirit and a desire for empowerment based on feminist thinking. Finally, the treatment of menstruation in poetic texts by three contemporary Galician authors - Lupe Gómez, Yolanda Castaño and Estíbaliz Espinosa- will be analyzed.

Keywords: Galician poetry, female body, menstruation, taboo, transgression

\section{I.- INTRODUCIÓN. PRESENZA DO CORPO FEMININO NO IMAXINARIO LITERARIO}

A presenza do corpo feminino no imaxinario literario articúlase basicamente en dous eixos opostos. A grandes trazos, atopamos por unha banda a imaxe dun corpo outro creada polo discurso tradicional do patriarcado e, por outra, as representacións construídas na etapa contemporánea polo contradiscurso feminista desde a voz de eus femininos.

\section{1.- A tradición patriarcal sobre o corpo das mulleres}

Na primeira das liñas de representación á que nos acabamos de referir, a tradicionalmente producida no marco do discurso patriarcal, a muller está presente ben como obxecto de desexo ou idealización, ou ben como obxecto temible, odioso ou minusvalorizada mais, en calquera caso, como obxecto. Esta liña de representación mostra o corpo feminino conforme determinados estereotipos e, sobre todo, desde unha ollada allea, no marco dun discurso falogocéntrico. E esta construción do feminino (que implica a exclusión de determinados elementos considerados tabú) fundaméntase en marcadores da diferenza: isto é, ese discurso establecía unha división binaria, colocando o masculino do lado da razón e o intelecto, do espírito, da humanidade, do sólido, estable, do activo e público, fronte ao feminino que se atopa submetido ao irracional, vinculado á materia, á animalidade, ao variable e inestable, ao pasivo, ao privado. Para Rosi Braidotti, a desviación respecto da masculinidade normativa dos corpos femininos é catalogada como anomalía no sistema patriarcal, de modo que a muller, en tanto que diferente, é considerada monstruosa, capaz de provocar asemade atracción e repulsión, fascinación e horror (Braidotti 1987: 65). Esta monstruosidade pasa a converterse en signo de inferioridade, dado que «[w]ithin this dualistic system, monsters are, just like bodily female subjects, a figure of devalued difference» (Braidotti 1987: 64).

Esta diferenza serve para fundamentar a caracterización pexorativa e mesmo misóxina sobre as mulleres en todas as ordes do discurso patriarcal e falogocéntrico ${ }^{2}$. A muller, o feminino definido como outro (anómalo e monstruoso,

2 «The topos of women as a sign of abnormality, and therefore of difference as a mark of inferiority, remained a constant in Western scientific discourse. This association has produced, 
como vimos), equipárase polo tanto ao corpo que, expulsado das esferas do poder, está condenado a ser controlado por eses poderes como obxecto (nunca suxeito), privado mesmo da posibilidade de auto-definirse ${ }^{3}$. A esta vinculación entre discursos de exclusión e de domesticación refírese tamén Meri Torras, quen afirma:

no resulta impropio advertir que el establecimiento de los discursos de poder-saber que expulsan el cuerpo - y a las mujeres - de su feudo van emparejados con la eficacia operativa de unos discursos normativos destinados prioritariamente al control y a la domesticación de los cuerpos, en especial de aquellos sujetos - y apenas sujetos, como las mujeres o los individuos marcados por una diferencia étnica o de práctica sexual - asociados, incluso identificados, con la preeminencia material-natural-pasional-bárbara del cuerpo sobre la razón. (Torras 2006: 12; cursiva no orixinal)

E nese ámbito do indicible, do tabú verbal, do íntimo e do corpo-natureza encontraríanse os órganos sexuais e reprodutores das mulleres, mais, por riba de todo, os fluídos menstruais. A carga negativa que se asocia á menstruación é ben patente na maioría das culturas, occidentais e orientais (Thiebaut 2017; Seara2016), incluída a galega. Esa marca, chea de significado pexorativo, afecta fundamentalmente á (in)visibilización da menstruación e esténdese a todas as sociedades patriarcais en forma de tabú, silenciamento e eufemismo, nun estigma social que pervive ata hoxe (Johnston-Robledo + Chrisler 2011: 10-14).

Desde a antropoloxía, documentouse a existencia de preconceitos e estigmas milenarios sobre a menstruación, tradicionalmente vinculada ao impuro e abxecto. Destácase o «horror que inspira la mujer menstruante» ás diferentes relixións, sociedades e civilizacións, ao longo da historia e nas diferentes latitudes xeográficas (Roux 1990: 55), cunha recorrente vinculación coa impureza desde a ollada dos varóns, a ollada normativa. Paradoxalmente, o sangue menstrual pasou de ser celebrado inicialmente como sinal de vida e fecundidade nalgúns cultos da antigüidade, a ser considerado impuro e, polo tanto, tabú. Ponse tamén de manifesto a existencia de crenzas profundas que vinculan a menstruación con poderes máxicos, con frecuencia asociados ao maléfico, ao oculto e maldito. O significado simbólico do sangue como elemento vital, cuxo derramamento constituía un signo de morte, sustenta o enraizamento deste grande pavor, combinado co feito de que a experiencia da menstruación era irreproducible e incomprensible desde a vivencia masculina. Deste xeito, o

\footnotetext{
among other things, a style of mysogynist literature body (...)» (Braidotti 1987: 63). Máis adiante, Braidotti afirma que a misoxinia é unha necesidade estrutural nun sistema, o patriarcal, que só representa o outro como negativo: «the mysogyny of discourse is not an irrational exception but rather a tightly constructed system that requires difference as pejoration in order to erect the positivity of the norm» (Braidotti 1987: 64).

3 "In the binary structure of the logocentric system, "woman", as the eternal pole of opposition, the "other", can be assigned to the most varied and often contradictory terms. [...] "Woman" is that which is assigned and has no power of self-definition. "Woman" is the anomaly that confirms the positivity of the norm» (Braidotti 1987: 67).
} 
sangue menstrual (fluído inequivocamente vinculado á fisioloxía feminina nunha etapa da vida) acordou universalmente os temores masculinos. A xénese do tabú proviría da imposibilidade de asimilar un enorme paradoxo: se o derramamento de sangue provoca a morte, como entender un sangrado periódico xurdido sen ferida, que se vincula coa vida? Segundo afirma Seara, «o fluír do sangue sen dano previo reafirma a nosa dependencia da natureza» (2016: 151) e, polo tanto, evidencia a imposibilidade da liberdade absoluta. Establécese así unha xerarquía entre o sangue menstrual, por unha banda, e o procedente da violencia e a guerra, por outra. Se o primeiro é obxecto de rexeitamento pola súa impureza, o segundo vincúlase co masculino, co nobre e co heroico, nunha oposición que privilexia o masculino e que perdura no imaxinario ata a actualidade $^{4}$. En palabras de Émile Thiebaut, «la mise en concurrence des sangs menstruel et guerrier se révèle comme une manière plutôt ignoble d'établir une hiérarchie au profit de la classe des hommes» (2019). Pola súa banda, autoras como Ingrid Johnston-Robledo e Joan Chrisler sinalan os medios de comunicación e a publicidade como canais de actualización deste estigma, cando afirman: «Most of the attitudes these media convey are negative, and together they have constructed a stereotype of menstruating women, especially premenstrual women, as violent, irrational, emotionally labile, out-of-control, and physically or mentally ill» (Johnston-Robledo + Chrisler 2011: 11).

En definitiva, dese misterio vivencial nútrese o horror e o tabú que provoca, dun lado, e a consideración da súa irrelevancia desde o punto de vista masculino, doutro. Como resultado, ficaban fóra das representacións tradicionais do feminino determinados aspectos e fenómenos do corpo feminino: agochados no escuro e excluídos, non existían nin acontecían. Así, un órgano como a vulva - cuxa significativa revelación/ocultación foi exhaustivamente explorada por Mithu M. Sanyal no seu ensaio homónimo (2012) — ou a menstruación, de que vimos falando, caen do lado do non dicible.

${ }^{4}$ Thiebaut faise eco nos seus traballos da pervivencia desta xerarquización e da vitalidade dos prexuízose na Europa de hoxe e, sobre todo, nas redes sociais e entre a xuventude: «revient en force l'idée d'un sang menstruel toxique, signe d'une impureté qu'il faudrait purger, et accréditant le lien entre déjection et sang menstruel. On est en plein dans Pline l'Ancien: le sang des règles donne la rage aux chiens, ternit les miroirs, fait tourner le vin, rouille le fer et transmet des maladies. Celles qui n'en ont pas honte sont forcément des sorcières ou des folles» (2019). Reproduce ademais a fotografía dunha pancarta exhibida na Manifestación \#NousToutes(París, 23 de novembro de 2019) e da que foi autora unha moza francesa, Emma Zahn. No cartaz expresábase a seguinte declaración: «Notre sang vous dérange seulement quand il vient de nos vagins» (Thiebaut 2019).

5 Segundo recolle esta autora, a estigmatización do sexo feminino na nosa civilización remóntase aos albores da tradición cristiá, na época de Agostiño de Hipona, e vincúlase coa represión da sexualidade feminina, para controlar os ciclos reprodutivos: "Con la finalidad de completar la depreciación de los genitales femeninos se planteó la pregunta de si las mujeres podían ascender al cielo con aquello que tenían entre las piernas» (Sanyal 2012: 64). A vulva, como encarnación e evidencia da sexualidade feminina e da súa capacidade de procreación, vinculábase ao infernal nun esquema de pensamento claramente misóxino. Sanyal chama a atención sobre o feito de que nas culturas occidentais contemporáneas non se teña consolidado no uso lingüístico unha denominación precisa, positiva e estandarizada da vulva (designada como «aí abaixo» ou con múltiples denominacións populares), nunha ausencia de «imaxe positiva» que chega practicamente 
O estigma, vinculado ben á impureza ou ben ao perigo, ten consecuencias negativas para o estatus social das mulleres até a actualidade, segundo afirman Johnston-Robledo e Chrisler: «the stigma and taboo of menstruation both reflects and contributes to women's lower social status» (2011: 13).

O tratamento dos fluídos menstruais nas artes e letras permítenos conectar coa idea do abxecto enunciada por Julia Kristeva, que o definía como aquilo que «perturba una identidad, un sistema, un orden. Aquello que no respeta los límites, los lugares, las reglas» (Kristeva 1988: 11, apud Moret 2000: 216).

\section{2.- Os contradiscursos a través dos suxeitos femininos}

Por outra banda, nunha nova liña de representación do corpo feminino sitúanse aquelas obras que se constrúen sobre a base dun $e u$ enunciador feminino, suxeito do discurso, construídas sobre os alicerces do discurso feminista, de modo consciente ou inconsciente. É aquí onde xorde a visibilización da especificidade, daquilo que tiña ficado excluído do dicible, reducido ao ámbito da ocultación e dos discursos elípticos do eufemismo. E esa representación no discurso implica existencia significativa. Para Chris Bobel e Elizabeth Arveda Kissling,

Shared cultural concepts and contexts give meaning to representation. From a feminist perspective, structures of language and habits of representation are among the pillars that hold up the kyriarchal system, within wich we live. These representations include more than sexist stereotypes in advertising and hyperthin models in fashion magazines, but the language we use — and not to use - in adressing the minutia of everyday life. (Bobel + Kissling 2011: 122)

Así, fronte á exclusión, fíxose necesaria unha resignificación, isto é, unha materialización do suxeito-feminino para as mulleres que se erixen en suxeito. Para iso, foi preciso construír un imaxinario propio, a través de novas estratexias para reconfigurar as imaxes, a caracterización e, con iso, as estruturas literarias convencionais.

Dentro de los límites impuestos por la representación de la mujer y las formas canonizadas de la literatura, la escritora ha debido crear intersticios en los cuales se insertan estratégicamente márgenes y palimpsestos, apropiaciones irónicas y voluntariosos espacios en blanco. Sin embargo, bajo la influencia de los nuevos movimientos feministas, las estrategias escriturales dieron paso al desafío de una rearticulación, tanto en el nivel de la imagen y la caracterización como en el de las estructuras literarias convencionales. (Guerra 2008: 42-43)

Foi preciso articular símbolos propios, ao non encontrarse naqueles símbolos do imaxinario patriarcal do que o universo (corporal e vivencial) feminino

ata a actualidade e que equivalería a unha invisibilización (ou mutilación) no plano simbólico (Sanyal 2012: 232). 
fora sistematicamente excluído: a escritora debe subverter, refundar, e para iso é indispensable dinamitar as barreiras, facer rebentar os límites simbólicos e os tabús (Guerra 2008). Para lograr isto, debeu elaborarse un contradiscurso que permitise expresar a identidade silenciada e, en calquera caso, etiquetada con condescendencia como «especificidade feminina». Neste camiño resultou primordial traer ao primeiro plano o corpo e a experiencia corporal, cos seus tránsitos,os seus ciclos e os seus fluídos. Introducíronse así os temas recusados, negados, desvalorizados e silenciados polo discurso falogocéntrico da escritura patriarcal. Para lograr esa transformación sería preciso que as mulleres escribisen o propio corpo sexuado (Cixous 1995), quebrando as prohibicións para darlle voz, visibilizalo e, así, afirmalo. As escritas feministas resultantes tentaron construír unha «nueva topografía del cuerpo en un discurso inédito del erotismo femenino», utilizando «la blasfemia y la parodia como expresiones subversivas y las utopías creadas desde su propia perspectiva, abriendo así una brecha en el denso campo intertextual dominante» (Guerra 2008: 43).

Esta (re)apropiación do corpo a través da súa visibilización literaria implica forzar e transgredir os canons, os modelos ou os xéneros establecidos. Trátase, en definitiva, de conseguir unha redistribución simbólica na que se inscriban e lexitimen todos aqueles elementos atribuídos ao xénero feminino polo imaxinario falogocéntrico (natureza, corporalidade, movemento cíclico) e tradicionalmente desvalorizados e, polo tanto, excluídos (Guerra 2008: 69-70). Nos ámbitos artísticos, incluíndo o literario, nace un novo imaxinario simbólico da sublevación para reverter estes discursos normativos. Temos de colocar as novas representacións do corpo, presentes nas mulleres poetas contemporáneas, no marco deste posicionamento.

E é aquí onde cabe situar a inclusión da menstruación no imaxinario simbólico, neste novo espazo de reivindicación a través da visibilización subversiva do tradicionalmente considerado indigno. Con esta nova perspectiva propiciada por novas xeracións de mulleres capaces xa de revisar os vellos mitos e supersticións, aflora por fin a exploración da menstruación como fenómeno digno de ser interrogado, útil para explicar unha parte da experiencia corporal e vital de boa parte das mulleres. Con certeza, o tema é complexo, por canto ten implicacións que remiten á tradición, á antropoloxía, á medicina, á relixión, á ideoloxía, á relación de control (ou non) do propio corpo, e tamén a cuestións como a maternidade e a non-maternidade ou a sororidade, por exemplo. Para alén disto, unha tal visibilización ten transcendencia política xa que

more generally, a focus on menstruation is part of a complex and enduring feminist project of loosening the social control of women's bodies, of working to move women's bodies from object to subject status-something absolutely foundational to a host of contemporary issues, from human trafficking to eating disorders to sexual assault. (Bobel +Kissling 2011: 123).

No ámbito da literatura contemporánea e, concretamente, da poesía o tema está presente, de xeito máis ou menos central, na obra de diversas autoras en diferentes linguas: de Maria Teresa Horta a Adília Lopes ou Paulina Chiziane, en portugués; de Gioconda Belli a Cristina Peri Rossi, en español; de Leire 
Bilbao a Estíbaliz Espinosa, en linguas peninsulares como o éuscaro e o galego, en textos adoito configurados desde a reivindicación e a subversión. Tamén no ámbito hispánico, publicouse a antoloxía Sangrantes (2013), editada por Luna Miguel, co propósito de dar visibilidade á menstruación na poesía.

No ámbito das artes presentáronse nas últimas décadas traballos artísticos de impacto mundial, focalizados na representación da menstruación. Boa parte deles sitúanse na liña do denominado activismo menstrual, desde os precedentes da obra plástica de Frida Kahlo (Henry Ford Hospital, por exemplo) á revolucionaria Red Flag (1971) de Judy Chicago, nos Estados Unidos. As manifestacións prodúcense en todo tipo de formatos: en libros, producións dixitais e audiovisuais (blogs, vídeos), mais sobre todo abundan nas artes plásticas e na fotografía. Entre as numerosas series fotográficas, son célebres a titulada Period (2015), publicada online pola poeta Rupi Kaur; Red Is the Colour, de Ingrid Berthon-Moine (2009); ou as exposicións The Curse / La Malédiction (París, decembro de 2014, Marianne Rosenstiehl) e Hic est sanguis meus / The Blood of Women (París, febreiro de 2017). Nas artes plásticas, obtiveron un importante impacto traballos de artistas como a portuguesa Joana Vasconcelos (A noiva, 2001-2005), as performances (Una mujer de rojo, de Una Pardo Ibarra, realizada en Colombia en 2012, entre outras), os vídeos da argentina Malena Pichot ("La loca de mierda"), alén de mostras do cinema de terror (Carrie, 1976, ou a saga Ginger Snaps, 2000-2004, por exemplo).

Por outra banda, publícanse numerosos estudos académicos (New Blood: Third-wave Feminism and the Politics of Menstruation, Chris Bobel 2010), textos ensaísticos-como Sang tabou. Essai intime, social et culturel sur les règles (Camille Emmanuelle 2017) ou La Révolution du féminin (Émile Froidevaux-Metterie, 2015)—e divulgativos (Ceci est mon sang, Élise Thiebaut, 2017, ou o manifesto asinado por Franka Frei, Periode ist politisch. Ein Manifest gegen das Menstruationstabu, 20206), entre outros traballos que analizan a significación na sociedade e na historia das mitoloxías e ideoloxías que envolven o tratamento da menstruación.

\section{II.- CORPO DE MULLER E PERSPECTIVA FEMINISTA NA LITERATURA GALEGA CONTEMPORÁNEA}

A literatura é un espazo de construción social, estética e ideolóxica, polo que ten a potencialidade de funcionar como un campo privilexiado de visibilización e unha oportunidade de empoderamento, un campo de debate especialmente propicio nunha sistema literario aínda non normalizado coma o galego. Para alén disto, Miguélez-Carballeira (2013) apunta a que o xurdimento de contradiscursos desde a conciencia de xénero se ve favorecido pola identifica-

${ }^{6}$ Esta publicación ten a súa base no traballo de investigación da autora (asinadoco seu nome oficial, Franziska Wartenberg) sobre tabús e menstruación na tese de mestrado Die Enttabuisierung eines Themas in Gesellschaft und Medien am Beispiel Menstruation defendida na Universidade de Berlín en 2018. 
ción da nación galega cunha figura feminina, a poeta fundacional Rosalía de Castro (1837-1885), quen foi obxecto dunha «codificación simbólica (...) como matria ou representación corpórea da nación» (Núñez Seixas: 812-13).

Na liña da revisión das mitoloxías e tabús patriarcais, na literatura galega actual consolidouse unha nova xeración de autoras que procuran naturalizar nos seus textos a experiencia e a reflexión sobre a representación do corpo feminino e dos seus fluídos marcantes. Esta visibilización encádrase nun proceso de (re) afirmación e de (re)construción da identidade feminina e da reivindicación do control e autonomía sobre o propio corpo. Esta nova abordaxe implica unha aceptación do corpo e esixe unha lexitimación do feminino en todas as súas manifestacións, reclamando a incorporación tamén da materialidade antes ocultada co a intención de subverter os modelos clásicos, os marcados polas convencións da tradición patriarcal.

Para moitas autoras galegas actuais, a asunción da escrita dos corpos fúndese coa experiencia dos corpos que se escriben. Este é o caso da poeta Ana Romaní, que desenvolve na súa obra unha poética do corpo-xénero, marcado pola reflexión «desde o xénero e desde o corpo» (Romaní 2011: 15). Romaní declara rotunda:

Todo corpo é político. Efectivamente pode ser que nun momento dado, en parte da poesía escrita por mulleres, urxise a necesidade de nomear o corpo desde outro lugar. Non sei se existe moita consciencia de por que se fixo así, pero nomear o corpo dotándoo dunha significación diferente é unha postura política. (Romaní 2011: 15)

Insiste Romaní logo en que estas representacións son «declaracións» políticas, polo que é necesaria unha lectura política. Esta unión de corpo e palabra está presente na obra das autoras galegas de autoría feminina contemporáneanomeadamente, nas obras poéticas, aínda que non só - , quen converteron o corpo en «territorio da identidade» emerxente e por tanto eixe central para a (de)construción (González 2009: 164) e campo de batalla.

En definitiva, a reivindicación activa da voz do suxeito feminino, dun lado, e a visibilización do corpo (mediante a introdución de temas antes silenciados

\footnotetext{
7 Atópase tamén na narrativa, como na novela Os corpos invisibles (Vigo, Xerais, 2019) da poeta e narradora Emma Pedreira, en cuxa obra a fusión entre palabra e corpo ocupa un destacado lugar. Nesta obra establécese un diálogo coa novela de Mary Shelley Frankenstein. O moderno Prometeo, para construír un corpo literario feminino feito de retallos de autoras británicas decimonónicas. O fantástico e a reivindicación feminista fusiónanse para crear un corpo literario con proxección de futuro, unha nova Prometea que articula sobre a «propia anatomía o calco dunha moderna criatura de ficción literaria e, desde aí, esta escritora multidisciplinaria que as revivirá a todas para colleitar por fin o éxito que a vida lles foi negando unha por unha» (Pedreira 2019: 116). No ámbito teatral, cómpre sinalar o espectáculo multidisciplinar Corpos disidentes (Nut Teatro, 2007), que propón unha reflexión crítica sobre a corporalidade e as identidades desde unha óptica feminina e antipatriarcal, ou, máis recentemente, a peza Kamouraska de Vanesa Sotelo (Inversa Teatro, 2013).
} 
ou minimizados) na enunciación poética, doutro lado, representan as dúas caras do mesmo fenómeno: a apropiación da enunciación en feminino, ou dito doutro modo, a feminización da enunciación (Bermúdez 2013). Abórdase así a deconstrución dos mitos do patriarcado e a revisión da tradición e dos imaxinarios literarios, para situar o corpo-voz feminino nun lugar central. Desde a última década do século pasado, o tratamento da temática do corpo (erótica ou non) por parte das poetas galegas materializase «nunha expresión provocadora que non recusa ningunha das manifestacións posibles» (Dacosta 2008: 5), como acontece nas poéticas de Olga Novo, Yolanda Castaño ou Lupe Gómez, entre outras.

Por outro lado, temas tradicionalmente femininos, mais moi pouco presentes na poesía como pode ser o embarazo, o parto, o rol materno, a non maternidade, o aborto, a menstruación, etc. atopan o seu lugar e son revisitados e vistos desde novas perspectivas... Aparece o que poderiamos chamar orgullo de muller, por dicilo así, e o adxectivo feminino, aínda que continúa sendo problemático, empeza a perder as súas connotacións pexorativas ao aplicarse á literatura. (Marçal 1998: 70-71)

\section{III.- REIVINDICAR E TRANSGREDIR: O CORPO, BANDEIRA E CAMPO DE BATALLA}

Un breve repaso a algúns dos poemarios contemporáneos ofrécenos exemplos dunha nova orientación no emprego do léxico referido ao corpo, que chega da man da irrupción das temáticas corporais: títulos como Levantar as tetas, $O$ útero dos cabalos, Os teus dedos na miña braga con regra ou Pornografía, de Lupe Gómez; Corpos transitivos, de Elvira Riveiro Tobío; ou A teta sobre o sol, de Olga Novo, son testemuño do afloramento de novas estratexias de apropiación da palabra desde unha óptica feminista ás que nos referimos anteriormente.

Neste traballo centrarémonos no tratamento do fenómeno da menstruación nas poéticas de Lupe Gómez, Estíbaliz Espinosa e Yolanda Castaño. Nalgúns poemas destas autoras, o ciclo e o fluído menstrual preséntanse vinculados a diversos elementos: a caracterización como marca feminina, a dor, a transgresión e a indisciplina (social, individual) e a provocación orientada á subversión. Como substrato latexa, en todos os casos, unha máis ou menos explícita vontade reivindicativa, ao servizo da ocupación de espazos públicos para as mulleres, como se ten apuntado (Seara 2013 e 2016).

Lupe Gómez (1972) móstrase perfectamente consciente do seu acto de rebelión, como expresa en Poesía fea: «a historia non deixou falar ás mulleres e agora deixamos de calar» (Gómez 2000: 117). Gómez sitúase, especialmente, na transgresión máis radical dos modelos establecidos — das normas sociais e do discurso poético-, no que se denominou pornoprovocación (Almeida + Baltrusch 2005: 8). Esta estratexia consiste nunha subversión das convencións estéticas mediante unha desinhibida verbalización do corpo feminino, dos 
aspectos estigmatizados da súa físioloxía e, por último, dos seus fluídos como bandeira $^{8}$ de identidade do suxeito poético, como salientou Seara (2013 e 2016). Gómez explicítao claramente: «Eu quixen limpa-la palabra menstruación. Liberarme e liberarnos — homes e mulleres- das ataxes» (Gómez 2000: 37). Atopamos diversas mostras desta visibilización en Os teus dedos na miña braga con regra (1999), por exemplo:

Gústame incomodarme,

levantar a miña saia,

abrir a miña braga

e ver o río.

A humidade onde

dentro de min

non hai ninguén. (Gómez 1999: 46)

Coa súa reapropiación verbal dos fluídos corporais - e a través deles, do propio corpo-, Gómez expresa «o conflito, o tránsito, a rebelión, a fondura do esgazamento coas convencións eco mundo circundante» (Bermúdez 2013: 72), nunha transgresión que conduce á soidade e ao estrañamento. Así se transloce neste poema do mesmo volume, por exemplo:
Ninguén comparte
a miña fortaleza,
os meus músculos en tensión,
a miña cara inchada,
a miña barriga podre. (Gómez 1999: 19)

En Quero bailar, a autora reflexionaba sobre o seu concepto de poesía e sobre a súa práctica poética, indivisible da (súa) corporalidade:

A violencia dos meus poemas é a ferida inexistente. $\mathrm{O}$ mundo golpeando nos meus ollos. A hipocrisía abrindo en min un socavón, unha fenda. As guerras político-económicas que me rodean. Os fillos que non nacen. $\mathrm{O}$ mundo rural do que fun expulsada. A relixión, que me descubriu un mundo grande de pecados e culpabilidade. Todo iso que me rodea e que tanto dano me fai e que me fai sangrar polas noites. (Gómez 2006: 22)

De feito, Lupe Gómez innova «empregando o texto non só como un medio para representar o corpo, senón para consideralo xa en si corpo» (Almeida + Baltrusch 2005: 10). N'Os teus dedos na miña braga con regra escribe: «Poemas abertos, / os nosos corpos» (Gómez 1999: 81), afirmándose nunha fusión entre poesía e corpo que a autora confirma en fragmentos como o seguinte: «A miña autopoética é a miña vida e o meu sangue» (Goméz 2004).

8 Os tres versos do poema «Cruz vermella» conteñen unha clara asunción do fluído como elemento de identificación: «O sangue / da miña dor / é a miña bandeira» (Baltrusch 2013: 97; Gómez 1995 : 101). 
En paralelo a esta ruptura do tabú menstrual, na obra desta autora empréganse conceptos e vocabulario «inaxeitado», «inapropiado» (como «puta», por exemplo), aquel vinculado co abxecto socialmente e, polo tanto, absolutamente inesperado no ámbito público e máis aínda no discurso poético dunha muller. Gómez sérvese do abxecto para provocar e dinamitar as convencións. Na caracterización da menstruación coexisten en contrapunto adxectivos como «sucia e insoportable» con outros dotados de sentido positivo: «viva, / violenta / e libre» (Gómez 2000: 102). Como estamos a ver, as ideas de ruptura, violencia e a liberdade fúndense na poética da autora, quen se declara «algo violenta» con aquilo que escribe (Gómez 1999: 6) e, noutro lugar, manifesta a súa orientación cara á revolta: «Non quixen ser muller, víctima, buraco quieto. Quixen escapar. Decidín escaparme. Fuxir do cárcere e que nunca me encontraran. Vivir a miña vida sen que me dictaran o que digo» (Gómez 2004 : 14).

A esta exposición do tradicionalmente abxecto, agora lexitimado como aspecto con cabida no discurso poético, engádese en Gómez a invocación doutros elementos, profundando no nivel de abxección e de transgresión. Trátase de excrementos propiamente ditos, co que se intensifica o carácter subversivo e provocador da poesía fea da autora: «Quería ver poesía / chea de merda / e fun esa poeta maldita / chea de merda» (Gómez 1999: 61).

Na nosa consideración, Gómez sitúase así claramente na exploración da abxección, da transgresión mediante a invocación do maldito, o excluído, o prohibido, o silenciado e relegado á escuridade da negación.

Una literatura de lo abyecto se encuentra representada en los desechos, desperdicios, lo impuro, lo inmoral, lo interdicto. Las tres categorías de lo abyecto: alimentos, desechos y signos de diferenciación sexual corresponden a los impulsos erógenos orales, anales y genitales. Los alimentos, la materia fecal, la orina, el vómito, las lágrimas y la saliva generan lo abyecto. (Moret 2000: 217)

En definitiva, na escrita poética de Gómez a ruptura e a forte verbalización dun corpo-voz dotado de marcas de xénero lévase a cabo cunha violencia directamente proporcional á potencia das normas establecidas, á súa capacidade de opresión, negación e silenciamento.

Cunha perspectiva diferente, na obra poética de Yolanda Castaño (1975) aflora tamén a menstruación, que se aborda desde o erotismo, dun xeito intenso, desinhibido e unido ao pracer sexual, transgredindo dese xeito o milenario tabú de impureza e intocabilidade. De feito, o estigma social sobre a menstruación ten como unha das súas manifestacións o rexeitamento ou a autocensura no relativo ás relacións sexuais nese período, tal como sinalan Johnston-Robledo e Chrisler: "Another consequence of menstrual stigma is observance of the sex taboo, that is, avoidance of intimate sexual relations during the menses» (2011: 13).

Polo tanto, a superación do repudio da xenitalidade «menstruada» para as relacións sexuais, ata o punto de erotizar o fluxo menstrual, significa na práctica unha rotunda transgresión dos tabús de autocontrol e de ocultación tradicionais. Estariamos ante unha das estratexias posibles para anular o estigma da menstruación na sociedade (Johnston-Robledo + Chrisler 2011: 14-16) 
Aplicando isto ao discurso literario, encontramos poéticas que incorporan este fluído no xogo sexual. Como sinala Seara, na poética de Yolanda Castaño desafíase a noción de abxecto para converter o fluxo vermello en fonte de vida e de pracer exquisito (2016: 153). En Vivimos no ciclo das erofanías (1998), Castaño poetiza explicitamente sobre o «fluxo de mapoulas» e integra o sangue menstrual cun papel visible e relevante no encontro erótico heterosexual (Castaño 1998: 25-26). A poeta-Gorgona chega entón a aleitar «esa mística ambición de vida», transformando o amante nun vampiro de cairos de morcego, «morcegáceos», para alimentalo deste modo co seu corpo: «eu menstrúo para alimentar / a túa bestial voracidade» (Castaño 1998: 25).

A menofilia vincúlase cunha voz poética erotizada, chea de poder, dadora de vida e portadora do sangue-alimento, fonte de transformación para o amante que bebe os líquidos da vida. Este empoderamento do suxeito feminino condúcenos ao tratamento do universo vampírico — conectado coa outredade escura dun sangue que funciona simultaneamente como signo de vida e morte- e de temáticas vinculadas co horror e co monstruoso, tamén presentes na narrativa galega. Nesta liña, a menofilia fúndese co vampirismo na novela Sangue 12 (2014), de Cris Pavón, na que a menstruación se relaciona co erotismo, co gozo e a forza vital, ao tempo que se pon en evidencia, máis unha vez, o estigma social ${ }^{9}$.

Pola súa banda, Estíbaliz Espinosa (1974) explora numerosas facetas da menstruación nos tres poemas ${ }^{10}$ incluídos na antoloxía Sangrantes de Luna Miguel. No primeiro dos textos, «/1 flood of blood/», o discurso poético xoga sobre os eixos da bioloxía e da xenealoxía, coa idea de fluencia como elemento central. Así, a voz poética lanza unha pregunta a unha antepasada, a avoa, nunha reflexión sobre o fluír da vida capaz de transcender ao plano colectivo:

Onde van os ríos que van dar ao teu sangue, avoa?

Tátara

tátara

tátara ti

tátara eu

tátarovula

tátaravoa?

9 «Refinei —outros dirían que pervertín — os meus modos no tocante á alimentación. Practiquei xogos inocentes e perversos con amigas menstruantes. Xa sabes como vai a cousa, repúgnalles un pouco ao principio, pero vanse deixando facer. O xogo adoita comezar por facérense as mortas. Eu desabróchoas con delicadeza, por mor de non manchar a roupa, o sangue límpase mal. Íspoas case por completo e, téñenas tan humilladas con "eses días" que, unha vez vencida a resistencia inicial, son felices de que alguén se achegue a elas precisamente "eses días"»(Pavón 2014: 172).

10 Trátase de «/1 flood of blood/», «/5 harakiris vasculares/» e «/período. inesperada forma de pera/», en versión orixinal galega e en castelán (Espinosa 2013: 87-102). 
Non perdoa, oh, himeneo, himes perforados por panos de fío. Sangue de liño. Que lin algunha vez, deslín algunha vez, fío de lectura, fío lúteo, onde. Onde van os ríos do sangue do teu sangue? Eu non sei. Pero van. Han ir. E van. E vou. (Espinosa 2013: 93)

Continuando nesa liña de posta en valor da xenealoxía en feminino, no poema «/período, inesperada forma de pera/» Espinosa cuestiónase sobre as posibilidades de articulación dunha escrita desde a experiencia feminina que, como vimos, se vinculaba tradicionalmente á natureza, ao material, alleo á elaboración artística e ás elevacións épicas (2013: 100-102). Alternando desde o inicio entre o eu individual e o nós plural que reúne o colectivo das mulleres, o poema comeza cunha pregunta e un aviso:

Podo aínda falar da épica de min cunha pinga de sangue a fumegar no chan do baño?

Podemos?

Que saibades logo

que no século XVIII saímos a cortar maionesas

por aí (Espinosa 2013: 100)

Con esta interrogación, levada a cabo pola voz colectiva dun nós feminino, equiparable a un nosoutras, incorpórase ao poema a cuestión do lugar da voz feminina na literatura. Cal sería a «épica» das sangrantes, da sinaladas pola impureza? Por outra banda, ábrese tamén a cuestión da compatibilidade entre linguaxe artística e representación do tradicionalmente oculto, de xeito que cabe preguntarse, con González, se «hai lugar na creación para un orgullo menstrual que supere o tabú, a vergoña e o abxecto que impón a idea de beleza e do moralmente aceptábel?» (2016: 85).

No poema, a pregunta vai seguida da propia afirmación de si mesma, xogando ironicamente a lembrar o poder atribuído (capacidade de «cortar maionesas»), ao tempo que se poñen en evidencia os prexuízos: «Somos un noxo. Cheiramos mal» (Espinosa 2013: 101). De feito, a denuncia dos prexuízos seculares sobre a abxección menstrual «de impureza chea» (Espinosa 2013: 102) constitúe un elemento fundamental do poema, tal como sinala Seara (2016: 152-53). Mais a exposición e a enunciación resultan liberadoras e o poema culmina explicitando a sublevación gozosa que implica a quebra dos tabús no propio poema, centrado na reflexión pública sobre o tema, para pecharse con este verso: «E fun má. E desobediente. E moitos bicos» (Espinosa 2013: 102).

Pensar a menstruación significa tamén pensar na posibilidade da xestación de vida, nun tándem que permite traer á superficie o posicionamento respecto da maternidade e das diferentes opcións das que cada muller dispón en relación con ela. A idea da non-maternidade apúntase tamén nesta poética: «Épica da regra: / un millón de ovos ao nacermos / seica un estrago de vida» (Espinosa 2013: 102). 
Destaca Espinosa a transcendencia da capacidade de xestación e, sobre esa base, a reivindicación dun vínculo histórico cunha extensa estirpe matrilinear, como sinala tamén Seara (2016: 140). A reflexión sobre a menstruación efectúase desde un punto de vista biolóxico e histórico, para facer fincapé no seu carácter de experiencia compartida na vida das mulleres desde a noite dos tempos. Como se ve, nestes textos incorpórase vocabulario científico, de xeito que encontramos terminoloxía procedente da bioloxía («mitocondrial», «gameto», «citoplasma» ou «feromonas», por exemplo) ao longo dos poemas. En todo caso, o máis salientable é que a expresión festiva, desinhibida, pracenteira ou mesmo dionisíaca, visibiliza e empodera o sexo da muller (que se nomea sen pudor mediante a palabra «cona») e exalta o poder dunha inmensa cadea de vida construída de nais a fillas nun fío que non acaba:

Que delicioso o bicho que rabuñou a nosa cona

Bebido nun vaso gutural de leite

pintadas de vermello, nalgún dos hemisferios

A Eva mitocondrial a agarrarse unha chea

comigo

E douscentos mil anos de nada correndo coma loucas (Espinosa 2013: 100).

As escollas léxicas e as imaxes seleccionadas nomean e traen para o primeiro plano os procesos agochados do corpo: pódese así «desovar un verso», poñendo en valor a potencia xenerativa, física e discursiva, dun discurso poético feminino.

\author{
(...) escribo isto \\ devecendo por que nos baixe dunha vez e a \\ todas á vez \\ -sincronizadas e uliscadas, feromonas vestidas \\ de seda \\ unha cousa mundial, premenstrual e peluda- (Espinosa 2013: 102).
}

Esta visibilización consciente forma parte dunha sublevación discursiva que persegue facerse presente, construír novos paradigmas e dar testemuña da propia existencia, significativa e xa nunca máis insignificante. O conxunto das representacións do corpo coinciden nunha revelación desinhibida, libre, consciente, provocadora e, na maioría dos casos, explicitamente orgullosa, como parte dun eu-muller reivindicativo do seu espazo na literatura e na sociedade. Como apuntan Johnston-Robledo e Chrisler, a enunciación pública dos fenómenos estigmatizados contribúe á autoaceptación e o empoderamento das mulleres (2011: 14). Particulamente no que respecta aos fluídos menstruais, nos textos destas autoras estes pasan de ser considerados estigma que debe ser ocultado con vergoña, a ser utilizados como bandeira, como enunciaba Lupe Gómez,para exhibirse como símbolo e estandarte de liberación (Seara 2013). 
En calquera caso, a intención crítica respecto do tabú e do estigma está no núcleo destas codificacións das imaxes deste fenómeno fisiolóxico. Isto tamén acontece nas artes plásticas, como ten suxerido Émilie Bouvard a propósito do recurso aos fluídos corporais por parte de diversas artistas contemporáneas:

[...] on peut ici suggérer que le recours aux humeurs est récurrent dans l'art des femmes, que celles-ci soient présentes réellement ou de façon figurée, et qu'il est assez évident qu'il s'agit pour ces artistes de tenir un discours, éventuellement critique, mais peut-être aussi autre, sur cette association millénaire et culturelle entre les femmes et les humeurs - et pas (sic) excellence le sang, et in fine celle qui leur est propre, le sang menstruel. (Bouvard 2010: 14).

\section{IV.- A MODO DE CONCLUSIÓN}

O tratamento da menstruación constitúe unha importante liña temática na produción nas últimas xeracións de poetas, en liña co realizado en diversos ámbitos lingüísticos e culturais do planeta nas últimas décadas, como se reflicte en diferentes antoloxías e iniciativas, sempre co pensamento feminista como pano de fondo, de xeito explícito ou implícito.

Nas abordaxes do fenómeno que acabamos de ver ponse de manifesto a súa resignificación como ferramenta para quebrar os límites estéticos e construír novos espazos simbólicos na literatura galega actual. Os textos de Gómez, Castaño e Espinosa materializan diversos enfoques, que teñen como punto en común a afirmación dun suxeito lírico explicitamente feminizado a través da exposición de vivencias e da nominación das marcas físicas de feminidade (como o fluído menstrual, entre outras).

Nun sistema literario como o galego, construído nunha lingua minorizada, resulta útil e necesario prestar atención ao papel do discurso literario como cristal privilexiado para romper cos modelos establecidos e coas subalternidades (sexan estas de xénero, lingüísticas, etc.). Co texto literario como un territorio de rebelión, especialmente para a escrita das mulleres, configúranse novos espazos simbólicos de autoaceptación e reivindicación. Unha mostra disto é a visibilización da corporeidade feminina, antes agochada e silenciada e agora abordada de xeito subversivo e mesmo provocador, colocando inclusive en primeiro plano os fluídos-tabú, aqueles vinculados ao abxecto e o indicible. Por medio desta materialización, en ocasións propositadamente violenta, imponse a construción dun novo discurso literario e social. Deste xeito, conséguese situar o corpo feminino nun lugar central do discurso literario e conquistar para o suxeito feminino un espazo no sistema.

En definitiva, asumindo as palabras de Chris Bobel e Elizabeth A. Kissling, cómpre recoñecer como significativa a representación da experiencia e fluídos menstruais: «[b]ecause menstruation matters. And so do the ways we talk about it, write about it, and illustrate it» (Bobel +Kissling 2011: 121). 


\section{BIBLIOGRAFIA}

Almeida, A. B. Simões de + Baltrusch, B. (2005) «Aproximación crítica á obra de Lupe Gómez. Atentado ao culturalismo», Anuario Grial de Estudos literarios galegos 2004,pp. 7-29.

Baltrusch, B. (2008) «Adília Lopes: Traducir entre la entropía y la subversión», Lectora. Revista de Mujeres y Textualidad, $\mathrm{n}^{\circ}$ 14, pp. 231-249.

Baltrusch, B. (ed.) (2013) Lupe Gómez: libre e estranxeira. Estudos e traducións, Berlín, Frank \& Timme.

Bermúdez Montes, M. T. (2013) «"E facemos regos, facemos versos”: Achegamento á autopoética da transgresión na obra de Lupe Gómez», en: Baltrusch, B. (ed.) Lupe Gómez: libre e estranxeira. Estudos e traducións, Berlín, Frank \& Timme, pp. 63-75.

Bermúdez Montes, M. T. + Carvallo de Sant'Anna, M. H. (eds.) (2016) Letras escarlata: Estudos sobre a representación da menstruación, Berlín, Frank \& Timme.

Bobel, C. + Kissling, E. A. (2011) «Menstruation matters: Introduction to Representations of the Menstrual Cycle», Women's Studies: An inter-disciplinary journal, 40:2, pp. 121-126. Dispoñible en: http://dx.doi.org/10.1080/00 497878.2011.537981 [xaneiro 2020]

Bouvard, É. (2010) «Présence réelle et figurée du sang menstruel chez les artistes femmes : les pouvoirs médusants de l'auto-affirmation». Comunicación presentada na xornada de estudos en «Les fluides corporels dans l'art contemporain». Institut national d'histoire de l'art (INHA), París, 29 de xuño de 2010. Dispoñible en: https://hicsa.univ-paris1.fr/documents/ pdf/PublicationsLigne/Pr\%C3\%A9sence\%20r\%C3\%A9elle\%20et\%20 figur\%C3\% A9e \%20du\%20sang $\% 20$ menstruel $\% 20 \mathrm{chez} \% 201 \mathrm{es} \% 20 \mathrm{ar}-$ tistes\%20femmes-Emilie\%20Bouvard.pdf [decembro 2019].

Braidotti, R. (1987) «Mothers, Monsters and Machines», en Conboy, K.+ Medina, N. + Stanbury, S. (eds.) Writing on the Body: Female Embodiment and Feminist Theory, New York, Columbia University Press, pp. 59-79.

Castaño, Y. (1998) Vivimos no ciclo das erofanías, A Coruña, Espiral Maior.

Cixous, H. (1995 [1975]) La risa de la medusa. Ensayos sobre la escritura. Traducido por A. M ${ }^{a}$ Moix, Barcelona, Anthropos, Madrid, Consejería de Educación. Dirección General de la Mujer, San Juan, Universidad de Puerto Rico.

Dacosta, M. (2008) «Da voz e da man das mulleres. As escritoras galegas á procura dun espazo propio», A Habana, 23 de febreiro de 2008. Dispoñible en: http://www.aelg.org/Centrodoc/GetParatextById.do;jsesionid=E394D458B FFE292E39829BCD96020F65?id=paratext2396.Centro de Documentación da AELG [novembro 2019]. 
Espinosa, E. (2013) «/período, inesperada forma de pera/»,en Miguel, L. (ed) Sangrantes, Jerez de la Frontera, Origami, pp. 100-102.

Frei, F. (2020) Periode ist politisch. Ein Manifest gegen das Menstruationstabu, Berlín, RandomHouse.

Gómez, L. (2012 [1995]) Pornografía, Santiago de Compostela, Positivas.

Gómez, L. (1999) Os teus dedos na miña braga con regra, Vigo, Xerais.

Gómez, L. (2000) Poesía fea, Santiago de Compostela, Noitarenga.

Gómez, L. (2004) Levantar as tetas, A Coruña, Espiral Maior.

Gómez, L. (2006) Quero bailar, Galicia, Lupe Gómez.

González Fernández, H. (2006) «Anatomía de tanta visibilidade das mulleres en literatura», Madrigal nº 9, pp. 69-72.

González Fernández, H. (2016) «Do silencio hixiénico ao orgullo da mancha. Censura e exceso na cultura menstrual» en Bermúdez Montes M. T. + Carvallo de Sant'anna, M. H. (eds.) Letras escarlata: Estudos sobre a representación da menstruación, Berlín, Frank \& Timme, pp. 83-103.

Guerra Cunningham, L. (2008) Mujer y escritura. Fundamentos teóricos de la crítica feminista, Santiago de Chile, Cuarto Propio.

Hernando, A. (1996) Cunnus. Represión e insumisiones del sexo femenino, Madrid, Montesinos.

Johnston-Robledo, I. + Chrisler, J. C. (2011) «The Menstrual Mark: Menstruation as Social Stigma», Sex Roles, 68(1-2), january 11th 2011 (online), pp.9-18. https://dx.doi.org/10.1007/s11199-011-0052-Z

Kristeva, J. (1988 [1980]) Poderes de la perversión, Buenos Aires, Catálogos Editora.

Marçal, Ma M. (1998) «Conferencia no I Encontro de poetas peninsulares e das illas», Festada Palabra Silenciada, n 14, pp. 67-72.

Miguel, L. (ed.) (2013) Sangrantes, Jerez de la Frontera, Origami.

Miguélez-Carballeira, H. (2013) Galicia, a Sentimental Nation: Gender, Culture and Politics, Cardiff, University of Wales Press.

Moret, Z. (2000) «Esos cuerpos escritos con sangre: del horror y lo abyecto en Gambaro, Álvarez, Eltit, Silvestre y Mendieta» en Suárez Briones, B., Martín Lucas, $M^{\mathrm{a}}$ B. + Fariña Busto, $\mathrm{M}^{\mathrm{a}}$ J. (eds.) Escribir en feminino, Barcelona, Icaria, pp. 213-232.

Núñez Seixas, X. M. (2014) «Rosalía e os emigrantes galegos: da polisemia da súa obra e do seu mito na diáspora» en Álvarez R. et al. (coords.) (2014). Rosalía de Castro no século XXI. Unha nova ollada, Santiago de Compostela, Consello da Cultura Galega, pp. 792-821. https://dx.doi.org/10.17075/ rcsxxi.2014. 
Pavón, C. (2014) Sangue 12 (2014), Santiago de Compostela, Urco Editora.

Pedreira, E. (2019) Os corpos invisibles, Vigo, Xerais.

Romaní, A. (2011) «Estremas fala da usurpación dos discursos, da linguaxe, dos corpos», Protexta,n¹7, pp. 14-17, 2011. Dispoñible en: http://temposdixital.com/td/protexta/protexta17.pdf [abril 2019].

Roux, J.-P. (1990) La sangre. Mitos, símbolos y realidades, Tradución de Marco-Aurelio Galmarini, Barcelona, Península.

Sayal, M. (2012) Vulva: La revelación del sexo invisible, Barcelona, Anagrama.

Seara, T. (2013) «"Libres, abertas, faladoras": presenza do corpo e da menstruación na obra de Lupe Gómez» en Baltrusch, B. (ed.) Lupe Gomez: libre e estranxeira: estudos e traducións, Berlín, Frank \& Timme. pp. 91-102.

Seara, T. (2016) «Sangue indócil: A menstruación e as súas imaxes literarias» en Bermúdez Montes M. T. + M. H. Carvallo de Sant'anna (eds.) Letras escarlata: Estudos sobre a representación da menstruación, Berlín, Frank \& Timme, pp. 133-157.

Thiebaut, É. (2017) Ceci est mon sang.Petite histoire des règles, de celles qui les ont et de ceux qui les font, París, La Découverte.

Thiebaut, É. (2019) «Etes-vous dérangée, dérangeant ou dégenré?»Le blog de Élise Thiebaut, 15/12/2019. Dispoñible en: https://blogs.mediapart.fr/elise-thiebaut/blog/151219/etes-vous-derangee-derangeantou-degenre?utm_source $=$ facebook $\&$ utm_medium $=$ social $\& u t m$ campaign $=$ Sharing $\&$ xtor $=C S 3-66 \&$ fbclid $=$ IwAR1OD_rbvFWrnnPyIP3kTZcgt9J6LHuMg1ZF-1_PkuMIut87fB-OA5Kucuk [decembro 2019].

Torras, M. (ed.) (2006) Corporizar el pensamiento. Escrituras y lecturas del cuerpo en la cultura occidental, Vilagarcía de Arousa, Mirabel.

Torras, M. (2009) El poder del cuerpo. Antología de poesía femenina contemporánea, Madrid, Editorial Castalia. 